American Journal of Pharmaceutical Education 2019; 83 (6) Article 7463.

\title{
COMMENTARY
}

\section{Authorship Considerations for Publishing in Pharmacy Education Journals}

\author{
Lana M. Minshew, PhD, Jacqueline E. McLaughlin, PhD \\ University of North Carolina Eshelman School of Pharmacy, Chapel Hill, North Carolina
}

Submitted December 5, 2018; accepted March 4, 2019; published August 2019.

\begin{abstract}
The distinction of authorship and its associated credit has important implications for academia. Pharmacy education encompasses faculty members from a wide and diverse range of disciplines, including the clinical, basic, and social sciences. These disciplines embody varying traditions and perspectives concerning who qualifies for authorship. As an academy, pharmacy education must do more to equip education researchers with the tools needed to navigate authorship decisions. The following commentary provides examples and recommendations concerning the issue of authorship within pharmacy education. We define authorship, examine authorship guidelines from health professions and education disciplines, and discuss authorship order. We then provide authorship recommendations for pharmacy education with the goal of supporting authorship decisions and further promoting discourse about authorship.
\end{abstract}

Keywords: authorship, reproducibility, collaboration, research, commentary

\section{INTRODUCTION}

The distinction of authorship and its associated credit has important implications for members of academia. Knowledge is advanced through scholarly discourse, ${ }^{1}$ making authors of scholarly work contributors to the collection of knowledge within and across disciplines. The number and impact of publications are often used as evidence of expertise, demonstrating a faculty member's ability to conduct research and help individuals obtain grant funding. ${ }^{1}$ Additionally, being an author can influence subsequent professional opportunities, such as invitations from a journal to peer review the work of others. The recognition associated with authorship is clearly significant, as scholarly publications and service are a central component for professional development and advancement in academia.

Pharmacy education encompasses faculty members from a wide and diverse range of disciplines, including clinical, basic biomedical and pharmaceutical sciences, and social sciences. These disciplines embody various perspectives and methodologies, along with customs and traditions, about who qualifies for authorship. ${ }^{1,2}$ Varying norms and expectations for authorship can result in conflicting views about who and in what order individuals receive authorship credit for contributions to research. The ongoing emphasis on interdisciplinary

Corresponding Author: Jacqueline McLaughlin, UNC Eshelman School of Pharmacy, University of North Carolina at Chapel Hill, Chapel Hill, NC 27599. Tel: 919-966-4577. E-mail: Jacqui_mclaughlin@unc.edu research further necessitates the need for authorship consensus when working with individuals from an array of disciplines as a means to mitigate disputes and grievances among collaborators. ${ }^{3}$

In the health sciences, more than 600 journals follow the authorship guidelines established by the International Committee of Medical Journal Editors (ICMJE). ${ }^{4,5}$ One hundred of these registered journals are pharmacy-related; however, only one has the word "education" in the title. Given the prevalence of authorship guidelines across the health sciences, the lack of guidelines or standards for pharmacy education is somewhat surprising. Authorship guidelines for pharmacy education could help generate consistent practice among scholars, provide clarity about individual contributions to scholarly work, and promote the quality and integrity of pharmacy education research.

This commentary provides examples and recommendations concerning the issue of authorship within pharmacy education. We define authorship, examine authorship guidelines from health professions and education disciplines, and discuss authorship order. Then, we provide authorship recommendations for pharmacy education with the goal of promoting discourse and providing support for decisions concerning authorship.

\section{Authorship Defined}

As the Authorship Guidelines of Harvard Medical School state, "[A] uthorship is an explicit way of assigning responsibility and giving credit for intellectual work" and is "important to the reputation, academic promotion, and 


\section{American Journal of Pharmaceutical Education 2019; 83 (6) Article 7463.}

grant support of the individuals involved as well as to the strength and reputation of their institution." In general, authorship standards acknowledge that not everybody who contributes to work resulting in a manuscript should be identified in the paper as an author. Guidelines and standards for authorship across multiple disciplines generally acknowledge that only those who made substantial intellectual contributions should be recognized as authors. These guidelines provide an array of qualifications for being named as an author in a paper, including the following: contributing to the conception or design of the study, participating in the acquisition or interpretation of data, drafting part of the manuscript, or providing approval of the final version of the manuscript (Appendix 1). The ICMJE guidelines, which are the most referenced guidelines in the health professions, state that authors must meet four criteria for inclusion on a publication: substantial contributions to the conception or design of the work; or the acquisition, analysis, or interpretation of data for the work; drafting the work or revising it critically for important intellectual content; final approval of the version to be published; and agreement to be accountable for all aspects of the work ensuring that questions related to the accuracy or integrity of any part of the work are appropriately investigated and resolved. ${ }^{4}$

Similarly, the American Psychological Association (APA) guidelines, the most common citation guidelines in education research, denote that authorship credit should only be granted to those that have actually performed and contributed substantially to the work. ${ }^{7}$ The APA's guidelines state, "authorship encompasses, not only those who do the actual writing but also those who have made substantial scientific contributions to a study ... [which] may include formulating the problem or hypothesis, structuring the experimental design, organizing and conducting the statistical analysis, interpreting the results, or writing a major portion of the paper." "Although the APA author guidelines do not have itemized criteria like the ICMJE, both identify that authorship credit should only be granted to those who provide a significant intellectual contribution to the study.

In addition, some universities have their own authorship guidelines as a means to promote consistency and awareness among scholars. For example, Yale's Office of the Provost and the Harvard School of Medicine have documents that define authorship, outline criteria for authorship and author order, and provide recommendations for how to handle authorship disputes. ${ }^{6,8}$ The Harvard School of Medicine, for example, indicates that individuals should post and include in their procedure manuals a description of how authorship and author order are determined. ${ }^{6}$
When contributions to a study do not meet criteria for credit as an author, individuals should still be acknowledged for their contributions to the scholarly work. ${ }^{4,7}$ Examples might include individuals who provide technical, editorial, moral, or financial support or advice without influencing intellectual aspects of the design, implementation, analysis, or interpretation of the specific study. Creating and communicating a standard for determining authorship and acknowledgements can help alleviate disputes between collaborators. ${ }^{3,9,10}$

\section{Over- and Underinclusive Authorship Practices}

Over- and underinclusive authorship practices (ie, including or excluding individuals on the author byline) are considered a significant threat to the integrity of research. ${ }^{11}$ Misrepresenting the contributions of scholars can have important implications for attribution, accountability, and career progression.

In medicine and nursing, an estimated $20 \%$ to $50 \%$ of published articles use overinclusive "honorary" authorships (also called courtesy, gift, guest, and prestige authorship). ${ }^{12-16}$ Honorary authorships are most commonly used to improve the visibility of research findings, increase the likelihood for a paper to be published, or curry favor with an individual (eg, including a well-known physician as an author to improve the likelihood of future collaboration). Authorship gifts may also be used to promote team cohesion, avoid conflict, and appear generous. ${ }^{11}$ However, they also may be coerced, as in cases where supervisors or senior faculty members pressure trainees or junior faculty members to include them as an author despite lack of contribution (ie, coercion authorship).

In contrast to honorary authorship, ghost authorship occurs when an individual that meets authorship criteria is excluded from the author byline. This can happen voluntarily when an individual declines the authorship or involuntarily when an individual is not offered the authorship. Common examples of ghost authorship include individuals who are independently hired to write all or portions of the paper, a trainee or subordinate directed to write a portion of the paper, and individuals who decline authorship to reduce the appearance of influence or conflict of interest. ${ }^{17}$

\section{Authorship Order}

Despite some consensus for what constitutes authorship on a scholarly paper, there does not appear to be a commonly accepted standard for authorship order. Many journals state that the authors should negotiate and decide together, and that the conversation of authorship order should be an ongoing discussion throughout the research 


\section{American Journal of Pharmaceutical Education 2019; 83 (6) Article 7463.}

process. However, there are key differences between authorship order across various disciplines. Most disciplines acknowledge first author (also called the lead author) as a significant stakeholder and main contributor to the scholarly piece. This is particularly salient in disciplines that use the APA's in-text citation format of using the first author's name within the text of the paper. The first author position on publications is so highly regarded that several publications are now allowing the use of co-authorship in order to demonstrate the equal role that two individuals played in developing and writing the scholarly work (eg, Journal of Biological Chemistry, Nature, Molecular Biology and Evolution).

Differences in authorship order between disciplines primarily lies in what happens after the first author position. For some disciplines, such as particle physics, mathematics, and theoretical computer science, authors are often presented alphabetically regardless of individual contribution to the work. ${ }^{9}$ In clinical and basic sciences, the last author in the list of authors is often called the senior author, which typically means that the work is conducted in that author's laboratory or research group under the individual's supportive guidance to the more novice researchers. ${ }^{2,10}$ This distinction makes the last author position one of high regard in clinical and basic sciences. In contrast, in education research, the order of authorship is often meant to reflect the relative contributions of the persons involved on the piece. ${ }^{7}$ According to APA, "the general rule is that the name of the principal contributor should appear first, with subsequent names in order of decreasing contribution."7 Therefore, in publications that adhere to APA style, the author in the last position identifies the individual who contributed the least to the scholarly work as an author.

Another important authorship role in the publication process is the corresponding author. The ICMJE defines the corresponding author as the individual who assumes primary responsibility for communication with the journal during the submission, peer review, and publication process. ${ }^{4}$ Additionally, the corresponding author is typically the point of contact for queries after publication, such as invitations to write commentaries, opportunities to respond to critiques (eg, letter to the editor), interests for collaboration, and requests for additional information about the research. ${ }^{4}$ As such, professional stability and expertise are important considerations for this role, which means that students, residents, postdoctoral fellows, and other trainees are generally a poor fit for corresponding author. When using APA authorship guidelines, this could mean that the second author is the most appropriate person to serve as corresponding author.
Views on the designation of corresponding authorship vary widely. ${ }^{18}$ In ecology, for example, papers with reprint authors from Asia are less likely to have first authors as corresponding authors when compared to papers from other geographic regions, such as Europe and the United States. ${ }^{18}$ While most organizations and journals do not associate notoriety or distinction with the position of corresponding author, research suggests that perception of authors' contributions can be heavily influenced by corresponding author designation. ${ }^{19}$ Bhandari and colleagues, for example, found that the first author was identified as contributing heavily to a study regardless of corresponding author designation; however, prestige and perception of the author's contribution increased significantly when the last author was designated as the corresponding author. ${ }^{19}$ This finding suggests that the role of corresponding author may indicate scholarly distinction.

The guidelines set forth by peer-reviewed journals in the health professions further highlight the differences between authorship norms in the sciences and education. The Journal of the American Medical Association, for example, encourages authors to be ordered according to norms in the basic and clinical sciences. ${ }^{20}$ In contrast, the journal Education in the Health Professions requires authors to be ordered according to relative contributions, as recommended by the APA. ${ }^{21}$ Furthermore, neither publication gives any scholarly distinction to the role of corresponding author. Both journals describe the corresponding author's role as serving a clerical purpose and as the point of contact for the submitted manuscript.

\section{Recommendations for Authorship in Pharmacy Ed- ucation}

Authorship guidelines are important because pharmacy education researchers come from various disciplines and often collaborate with individuals who have scholarly traditions different from their own. A lack of awareness concerning the influence of disciplinary norms on authorship practices may lead to confusion or misunderstanding as to the contributions of the listed authors in pharmacy education. Furthermore, the absence of consensus concerning authorship and authorship order in pharmacy education could result in conflict and confusion, making collaborations unnecessarily difficult and prohibitive.

Balancing the complexity of writing (eg, placing the research in proper context, using proper grammar and style, publishing in a journal of choice) with team science (eg, allocation of effort, trust between collaborators, resolving conflict) can be a complex undertaking. The following recommendations are specific steps we believe researchers can take to improve authorship practice and 


\section{American Journal of Pharmaceutical Education 2019; 83 (6) Article 7463.}

promote the integrity of authorship in pharmacy education. These are offered in hopes of helping scholars manage authorship decisions in their own research, determine their qualification as an author (or not) in collaborative projects, and facilitate discussions with research teams about authorship and authorship order.

Adopt the ICMJE Criteria. Every researcher should have a well-defined and defensible set of criteria for determining authorship as a project team lead or collaborator. The ICMJE guidelines (detailed above) are well vetted, widely accepted, and largely agreed upon as basic criteria for who should receive credit as an author. These criteria can be used to help research teams determine who qualifies for authorship. They can also help facilitate discussions with colleagues as authors plan, implement, and complete their respective work. By adhering to the ICMJE criteria for authorship, researchers can make expectations for authorship clear with collaborators. This may help with difficult conversations when an author needs to advocate for the inclusion of another author or the movement of an individual to the acknowledgements.

Further, pharmacy education and its associated journals should endorse and adopt these authorship criteria. In the absence of agreed-upon expectations and related training opportunities from the academy, scholars are challenged to decipher authorship practices and develop best practices on their own. Not only does this process waste time and resource, it can disadvantage and potentially discourage new researchers who are unprepared to navigate the unique challenges of authorship in pharmacy education.

Determine Authorship Order Prior to Starting. Having candid conversations and reaching agreement about authorship order prior to starting a project establishes expectations and can mitigate possible disagreements. It can also help shape the time commitment researchers allocate to a project. Because research roles and responsibilities can change over the course of a project, conversations about authorship order should be revisited numerous times throughout the research. The first or senior author should lead the group through the negotiation process for authorship order and take responsibility for documenting and following up with all coauthors. Identification of who will be the corresponding author should also be discussed during authorship negotiations.

When the writing process begins, revisiting these agreements and developing clear expectations for each author's contribution to the manuscript can promote positive working relationships while generating trust among collaborators. Further, author order should be explicitly agreed upon by all authors prior to submitting the work for publication. In cases when authorship or authorship order changes during the publication process (eg, during the revision process), steps should be taken to ensure that all authors on the work are aware of and approve the change. While most journals allow changes in authorship during the review process, they may also require authors to provide documentation explaining why the changes have occurred. For instance, BMC Medical Education allows for changes in authorship but requires that a change of authorship form be completed and signed by all authors, whether unchanged, newly added, or removed. ${ }^{22}$

Discuss Discipline Norms. Because pharmacy education embodies various backgrounds and disciplines, it is important to understand how authorship impacts faculty members' ability to be successful within and beyond their disciplines. If a faculty member has a background in education, for example, will that person's needs for authorship be different than those of a team member from chemistry? Faculty members should be prepared to discuss authorship preferences so that they can advocate for themselves and their professional needs in cases where project leads are willing to negotiate author order.

Determine Target Journal. The journal that is targeted could determine which authors are included on a paper and in what order. Research teams should work together to reach agreement on a target journal as some journals may have specific expectations with regards to who qualifies as an author and how authors are ordered. If there are no guidelines, the authors should work towards a plan for authorship order that everyone is comfortable with, as described previously.

Promote Authorship Transparency. Clearly, authorship can be a difficult process to navigate. To encourage transparency in how team members contributed to a publication, authors should explicate the contributions for each individual when submitting articles to journals for review. In addition, authors should consider denoting authorship criteria on professional documents, such as curriculum vitae, to help others better understand their scholarly contributions (eg, by including a footnote to the list of publications such as, "*First author indicates project lead and last author indicates senior author." or "*Corresponding author indicates senior author.").

Further, pharmacy education journals should require explanations for how each author qualifies for authorship. Some journals and disciplines already use this role identification process. For example, Journal of the American Medical Association, Medical Education, and PLoS One require that each listed author's contribution be identified at the time of submission and a list of the contributions are published with the final article. Explicating author 


\section{American Journal of Pharmaceutical Education 2019; 83 (6) Article 7463.}

contributions can help ensure that appropriate credit is attributed for the work, while mitigating ghost and honorary authorship. Additionally, the inclusion of author contributions will help dispel reader assumptions about an individual author's contribution to the scholarly publication (eg, corresponding author).

Know Your Institutional Expectations. Different institutions and types of institutions may value authorship and authorship order in different ways. As noted above, some universities have clear expectations for how authorship should be approached and documented while others do not. Institutions can also vary widely in their requirements for promotion and tenure, which can have significant implications for authorship and authorship order. Understanding their institution's expectations for promotion can help faculty member shape how they approach authorship discussions and decisions.

At the institutional level, schools of pharmacy must also have clear expectations regarding authorship and how it influences promotion and tenure decisions for those engaged in education research. While authorship expectations for tenure and promotion within a single school may vary to accommodate different specializations (eg, pharmaceutical sciences, education research, clinical practice), this should be explicitly acknowledged and accompanied by agreed upon requirements for professional advancement. Institutions should also document guidelines associated with institutional affiliation on publications in the event that an author changes institutions during the research or publication process.

\section{CONCLUSION}

Accurately identifying and representing the contributions of team members on scholarly work is critical for pharmacy education. Establishing expectations and common practices will help eliminate authorship disputes and promote consistency for how authorship is practiced and interpreted. As an academy, we must acknowledge the complexities of authorship and develop best practices for authorship and authorship order. We must work with one another, our institutions, and our professional bodies to improve authorship practice and ensure that individuals are appropriately recognized for their contributions to education research. This includes providing pharmacy educators with the training and tools they need to successfully navigate the authorship process, from the start of a research project to the completed publication. Through this important work, we can foster constructive research environments, empower scholarly productivity, enable trust in research products, and promote effective collaboration. It is our hope that this commentary advances discourse, promotes transparency, and improves authorship practice in pharmacy education.

\section{ACKNOWLEDGMENTS}

Lana Minshew, $\mathrm{PhD}$, served as first author on this paper. She led the preliminary literature review, facilitated the writing of the first draft, and provided critical review and approval of the final version. Jacqueline McLaughlin, $\mathrm{PhD}$, served as the senior and corresponding author on this paper. She contributed to the writing of the manuscript, participated in subsequent literature searches, and provided critical review and final approval of the final version. Dr. McLaughlin also assumes all responsibility for correspondence associated with this paper during and after the publication process.

\section{REFERENCES}

1. Uijtdehaage S, Mavis B, Durning SJ. Whose paper is it anyway? Authorship criteria according to established scholars in health professions education. Acad Med. 2018;93:1171-1175.

2. Altus MS. Culture of science and order of authorship. Sci Ed. 2001;24:17.

3. Smith E, Master Z. Best practice to order authors ion multi/ interdisciplinary health sciences research publications. Acct in Res. 2017;24(4):243-267.

4. International Committee of Medical Journal Editors. Recommendations for the conduct, reporting, editing, and publication of scholarly work in medical journals. http://www.icmje.org/icmjerecommendations.pdf. Published 2016. Accessed September 18, 2018. 5. National Academy of Sciences. Transparency in author contributions in science (TACS). Retrieved from http:// www.nasoline.org/about-nas/Transparency_Author_Contributions.html 6. Harvard Medical School OMBUDS Office. Authorship Guidelines. Adopted December 1999. Retrieved from https:// hms.harvard.edu/sites/default/files/assets/Sites/Ombuds/files/ AUTHORSHIP\%20GUIDELINES.pdf

7. American Psychological Association. Publication Manual of the American Psychological Association (6 ${ }^{\text {th }}$ ed.) 2010. Washington, DC: American Psychological Association.

8. Yale University, Office of the Provost. Guidance on authorship in scholarly or scientific publications. https://provost.yale.edu/policies/ academic-integrity/guidance-authorship-scholarly-or-scientificpublications. Accessed August 6, 2019.

9. Dance A. Authorship: who's on first? Nature. 2012;489:591-593. 10. Roberts LW. Addressing authorship issues prospectively: a heuristic approach. Acad Med. 2017;92(2):143-146.

11. Elliott KC, Settles IH, Montgomery GM, Brassel ST, Cheruvelil KS, Soranno PA. Honorary authorship practices in environmental science teams: structural and cultural causes and solutions. Account Res. 2017;24(2):80-98. DOI: 10.1080/08989621.2016.1251320 12. Eisenberg RL, Ngo L, Bankier AA. Honorary authorship in radiologic research articles: do geographic factors influence the frequency? Radiol. 2013;271(2):472-478.

13. Eisenberg RL, Ngo L, Boiselle PM, Bankier AA. Honorary authorship in radiologic research articles: assessment of frequency and associated factors. Radiol. 2011;259(2):479-486.

14. Kennedy MS, Barnsteiner J, Daly J. Honorary and ghost authorship in nursing publications. $J$ Nurs Schol. 2014; 46(6):416-422. 


\section{American Journal of Pharmaceutical Education 2019; 83 (6) Article 7463.}

15. Kornhaber RA, McLean LM, Baber RJ. Ongoing ethical issues concerning authorship in biomedical journals: an integrative review. Int J Nanomed. 2015;10:4837.

16. Wislar JS, Flanagin A, Fontanarosa PB, DeAngelis CD.

Honorary and ghost authorship in high impact biomedical journals: a cross sectional survey. BMJ 2011; 343: d6128.

17. Claxton LD. Scientific authorship: Part 2. History, recurring issues, practices, and guidelines. Mutat Res/Rev Mutat Res. 2005;589(1):31-45.

18. Duffy MA. Last and corresponding authorship practices in ecology. Acad Pract Ecol Evol. 2017;7(21):8876-8887.
19. Bhandari M, Guyatt GH, Kulkarni AV, et al. Perceptions of authors' contributions are influenced by both byline order and designation of corresponding author. J Clin Epidemiol. 2014;57:1049-1054.

20. Baerlocher MO, Newton M, Guatam T, Tomlinson G, Detsky AS. The meaning of author order in medical research. J Investig Med. 2007;55:174-180.

21. Education in the Health Professions. Instructions to Authors. http:// www.ehpjournal.com/contributors.asp. Accessed November 26, 2018. 22. BMC Medical Education. Authorship. https://

www.biomedcentral.com/getpublished/editorial-policies\#authorship. Accessed December 3, 2018. 
American Journal of Pharmaceutical Education 2019; 83 (6) Article 7463.

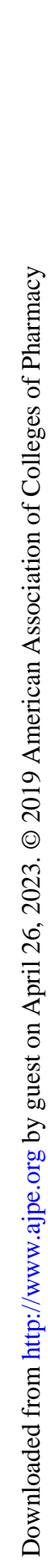
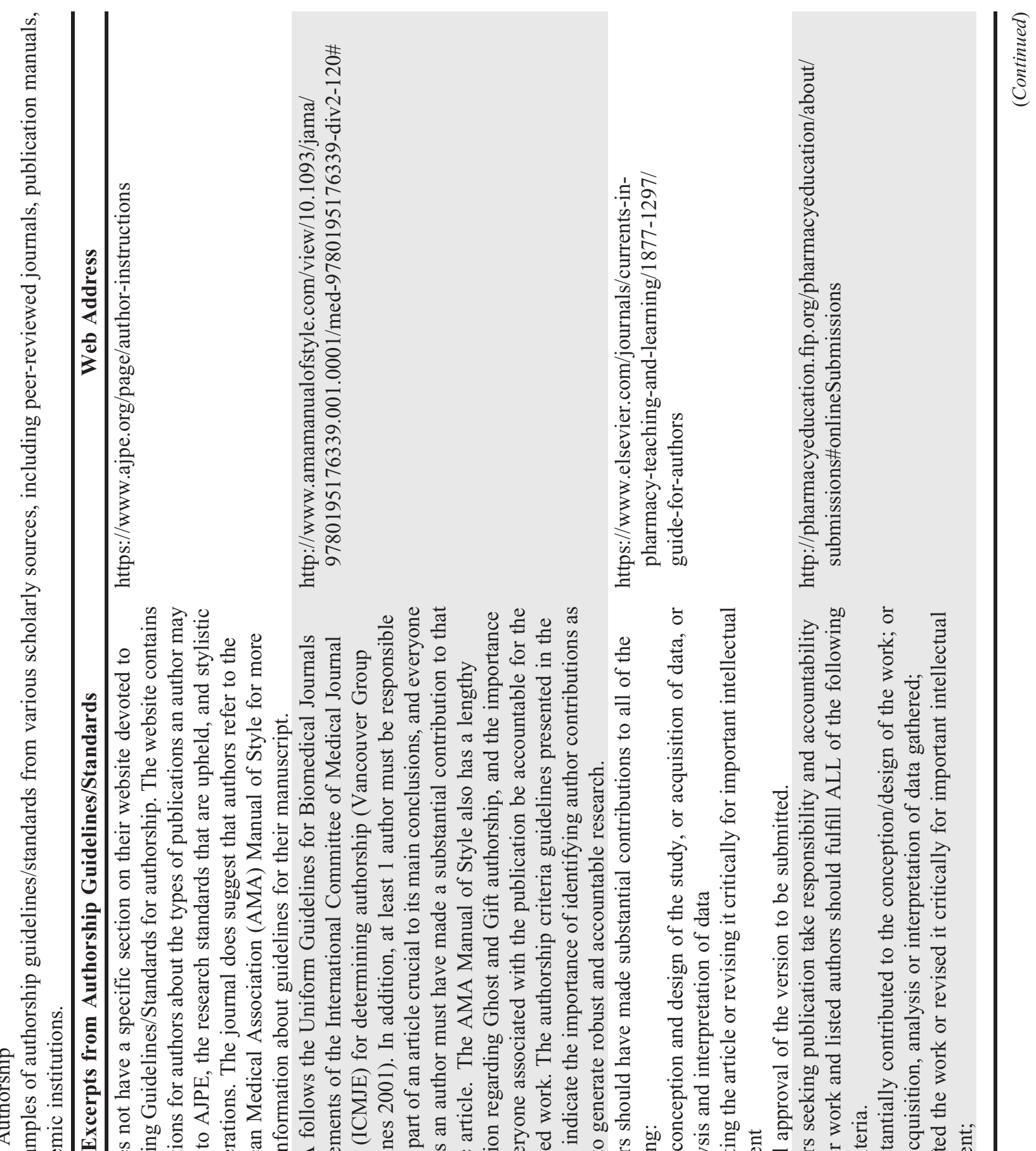

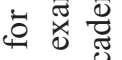

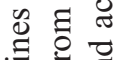

远

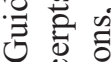

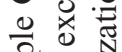

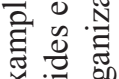

为宫

$\therefore$ 흐

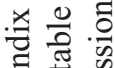

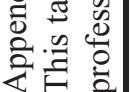

.

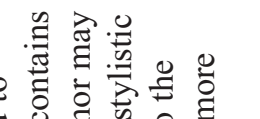

气

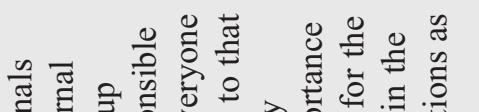

$\stackrel{0}{\rightleftarrows}$

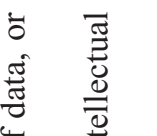

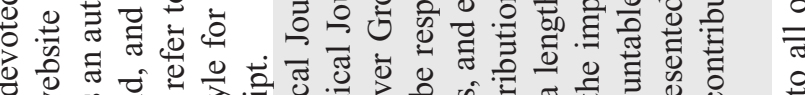

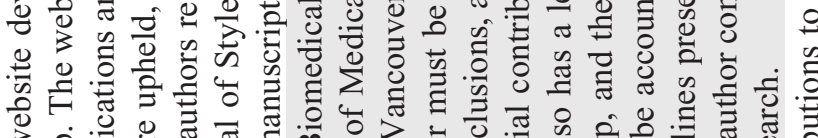

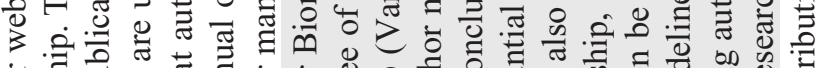

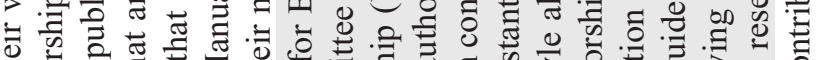

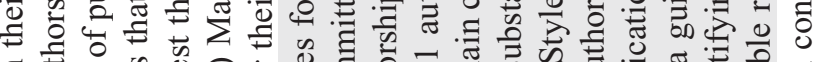

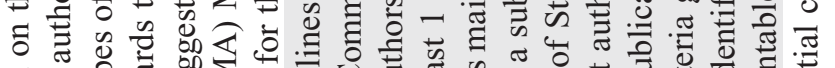
б

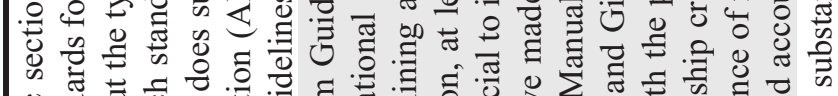

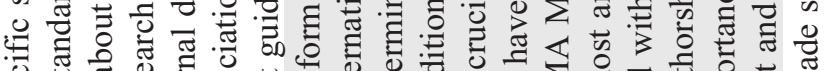

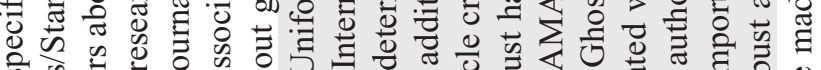

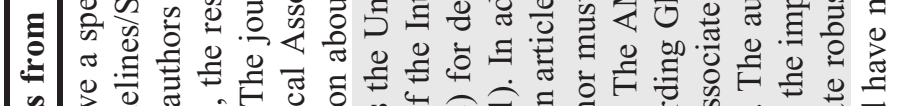

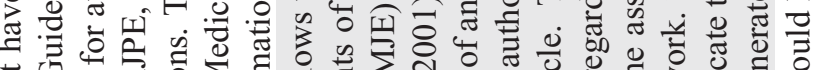

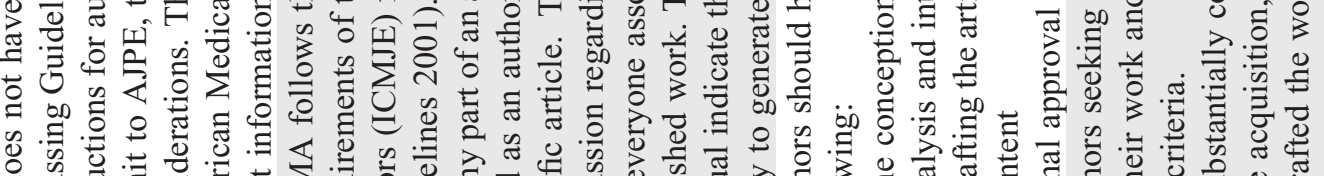

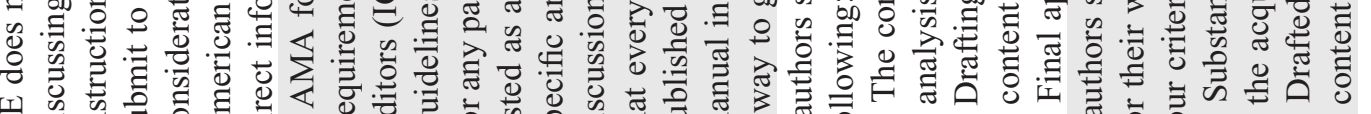

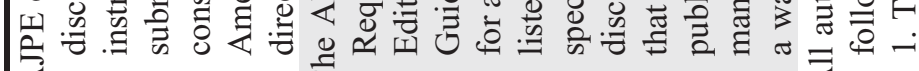

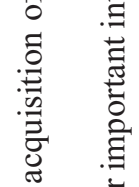

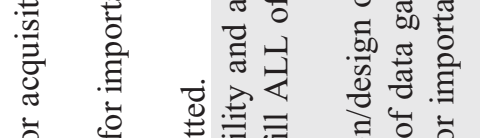

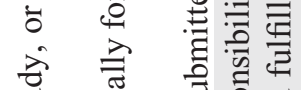

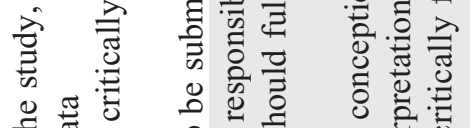

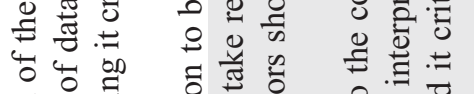

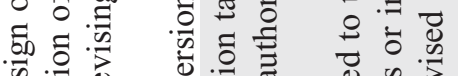
की

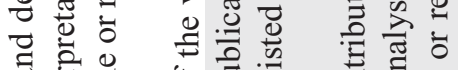

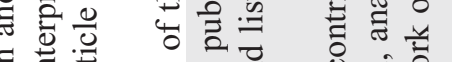

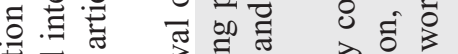

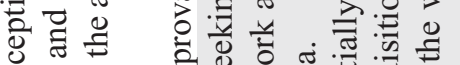
ฮิ 
American Journal of Pharmaceutical Education 2019; 83 (6) Article 7463.
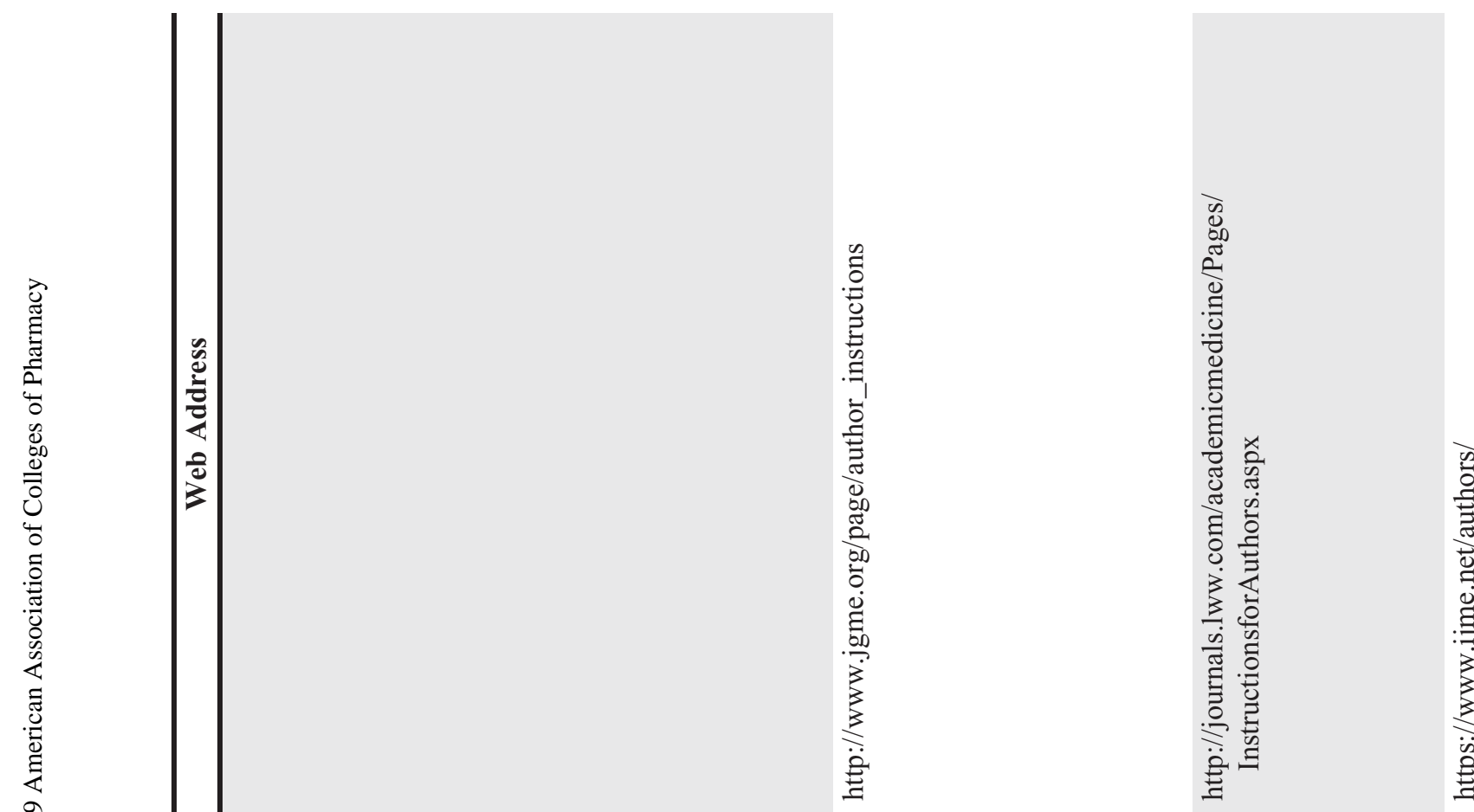

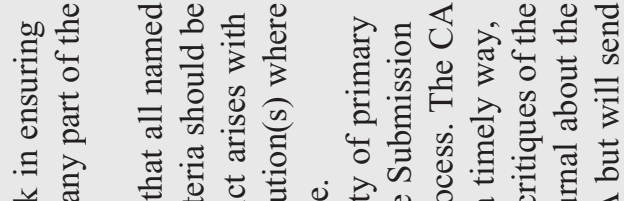

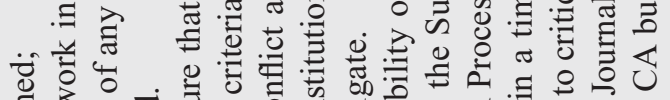
至 300
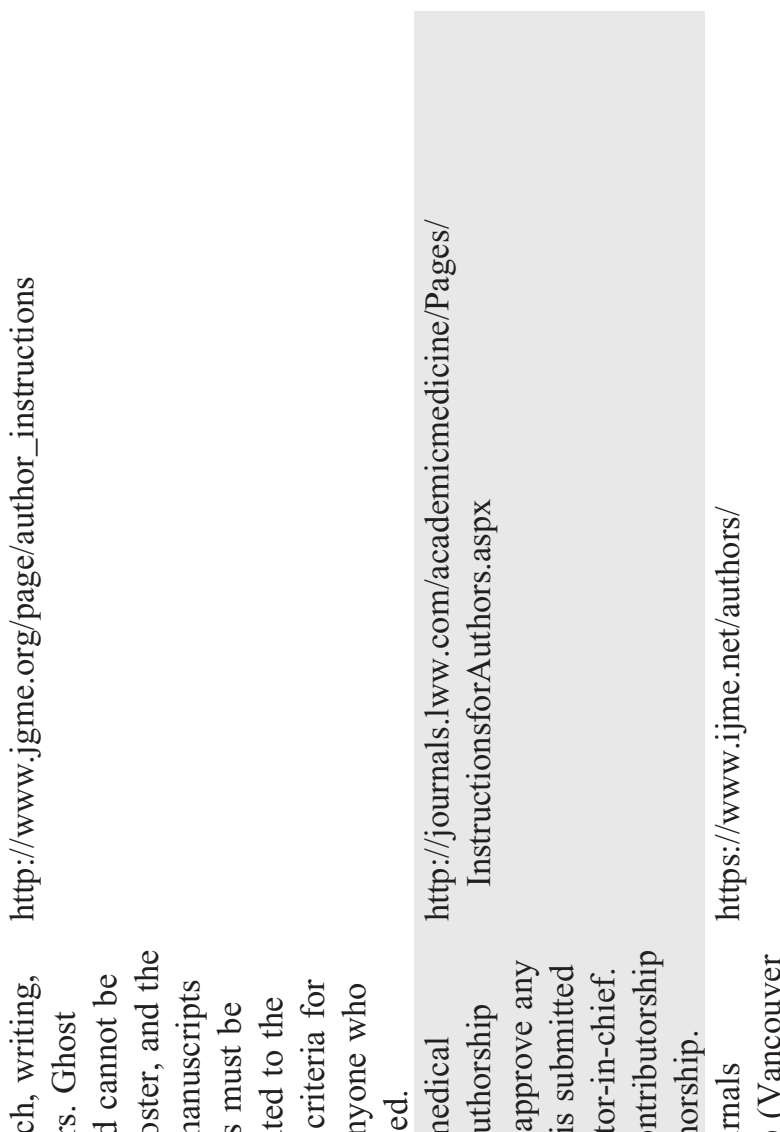

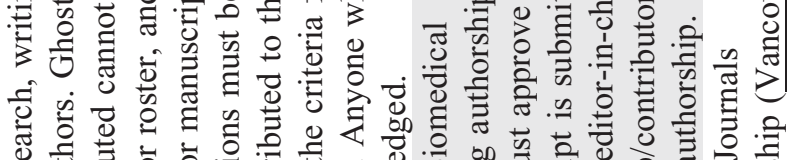

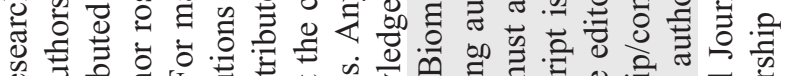

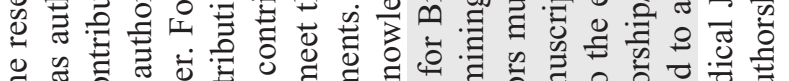

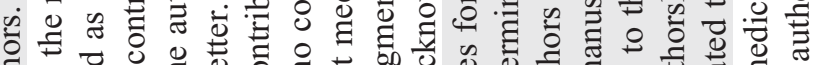

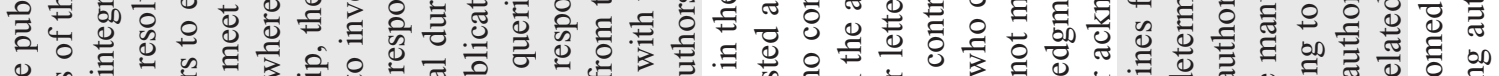

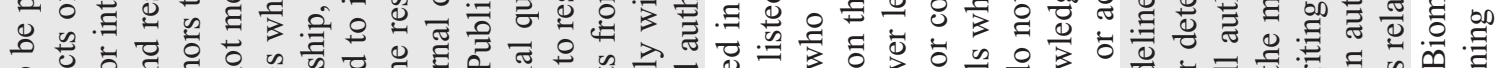

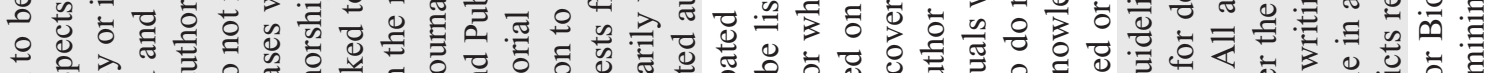

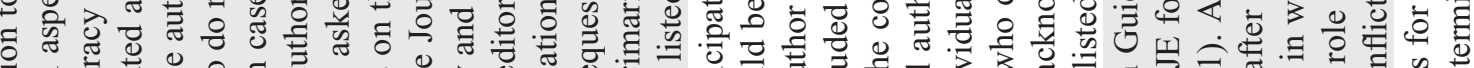
윤

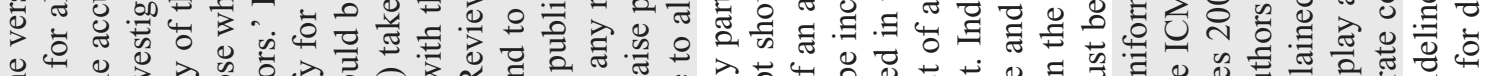

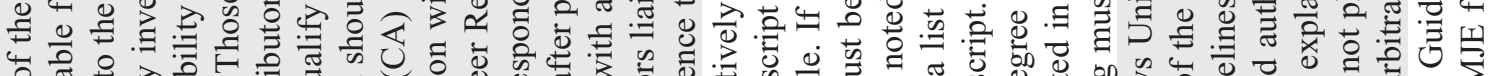
फ

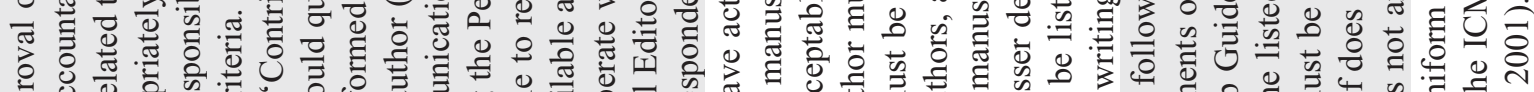

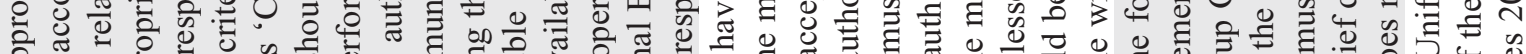
के

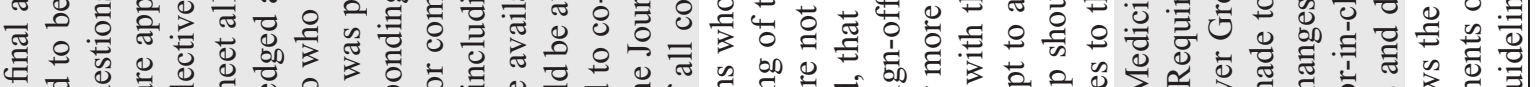
च च

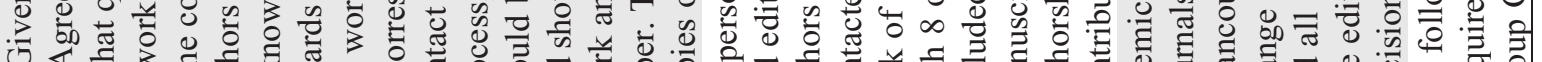

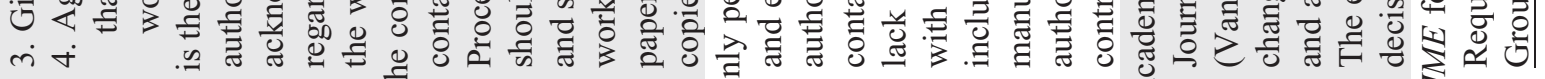
$\pm$ E
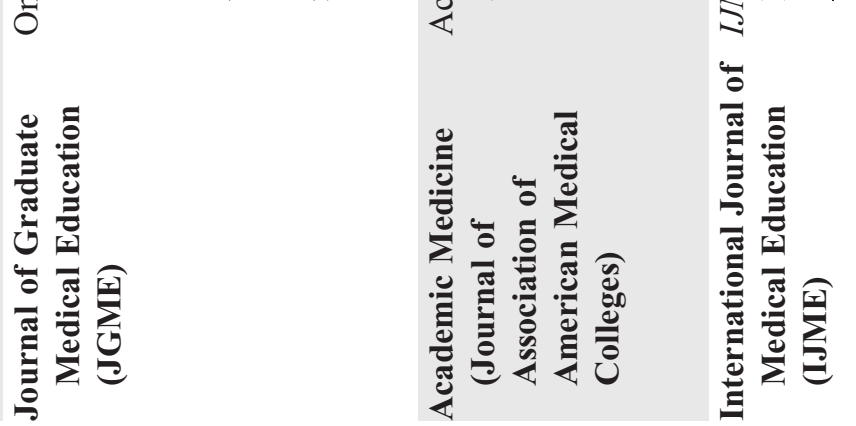
American Journal of Pharmaceutical Education 2019; 83 (6) Article 7463.

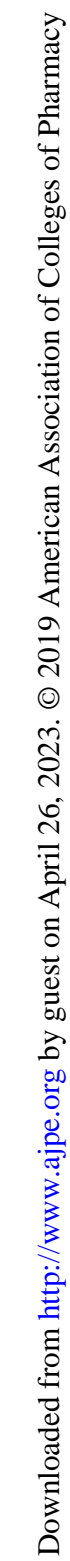

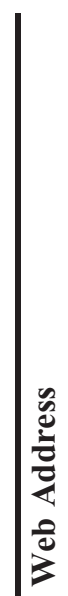

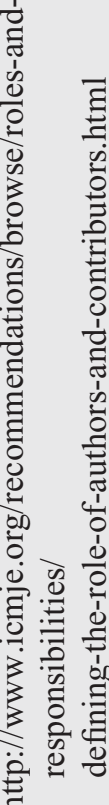

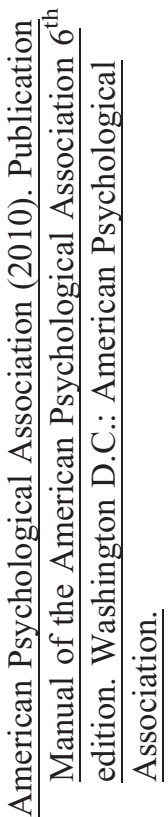

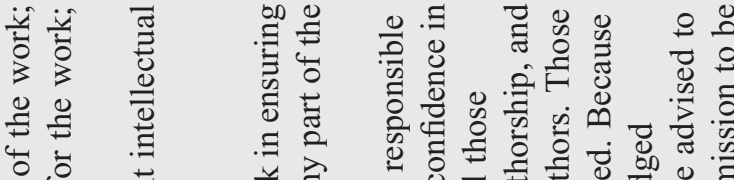

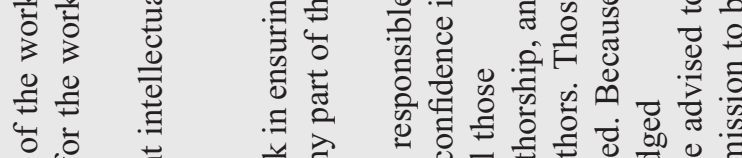

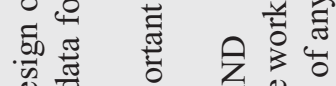

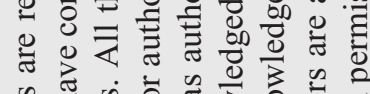

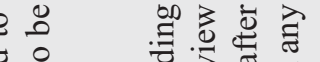

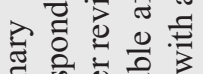

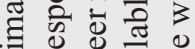

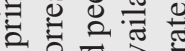

\%

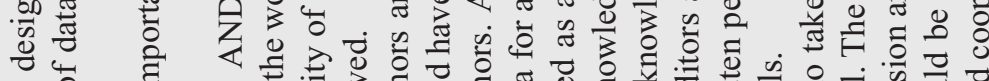

t。

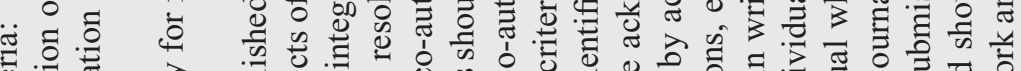

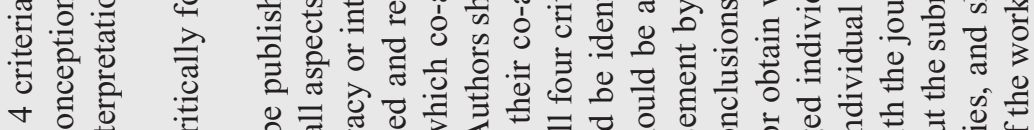

is $0 . \Xi$

ठ సٓ

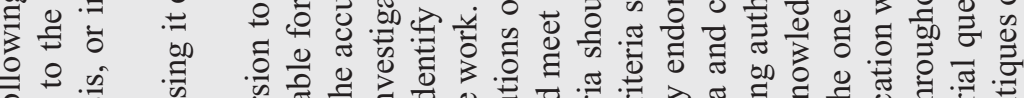

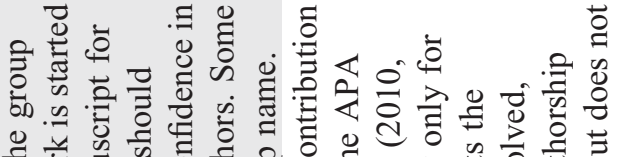

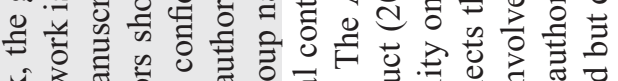

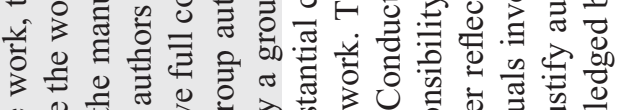

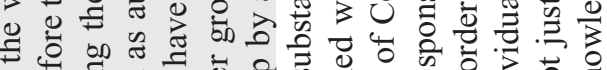

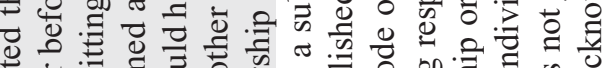

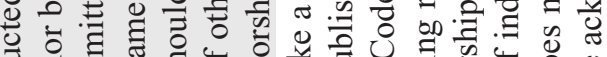

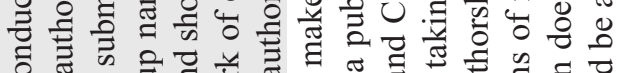

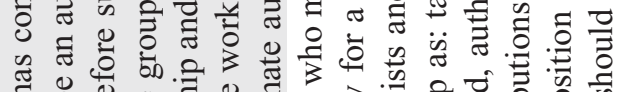

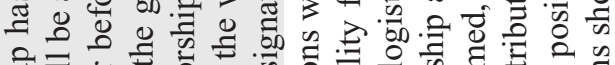

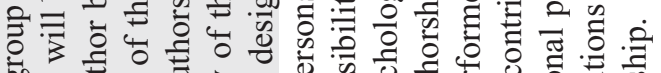

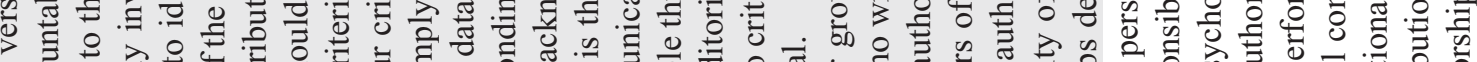

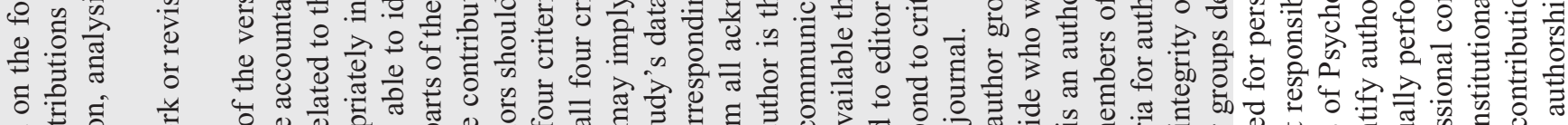

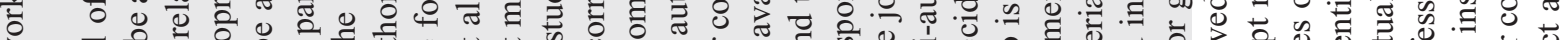

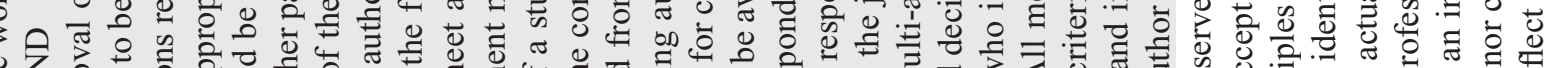

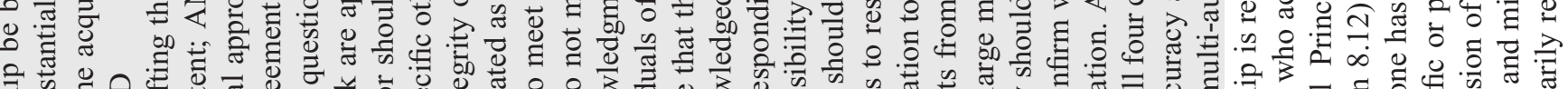

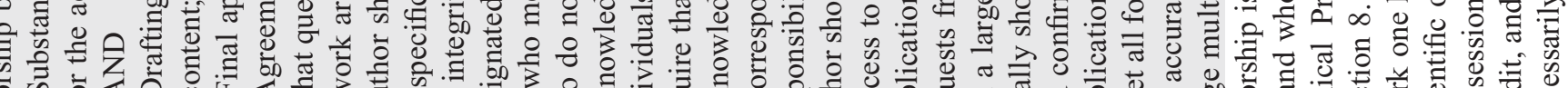

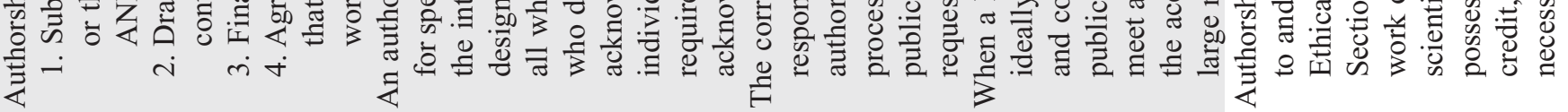

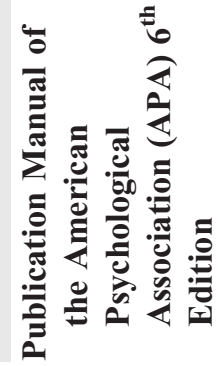


American Journal of Pharmaceutical Education 2019; 83 (6) Article 7463.

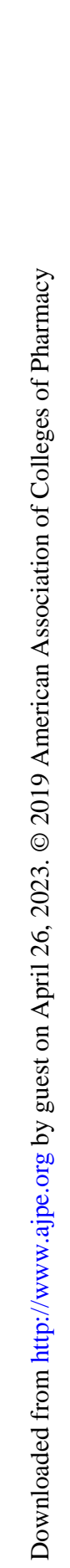

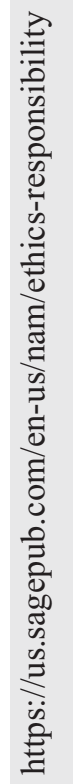

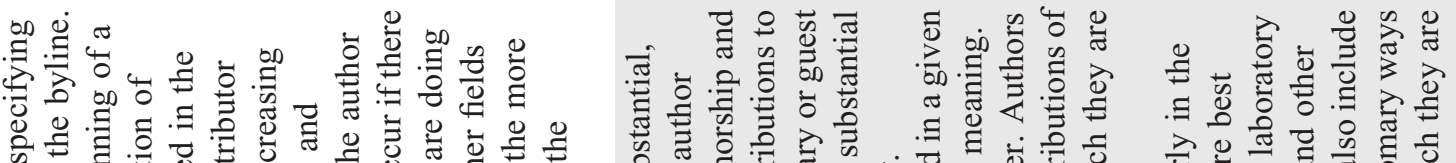

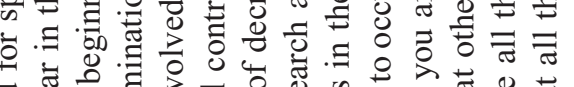

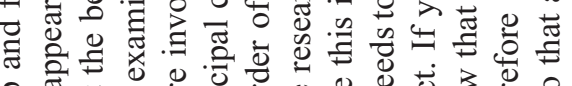

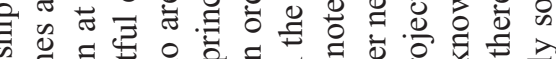

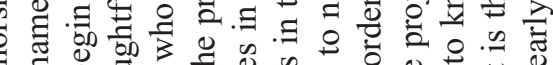

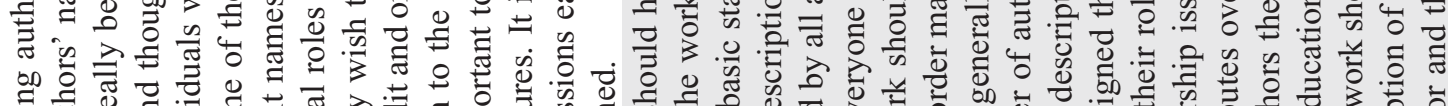
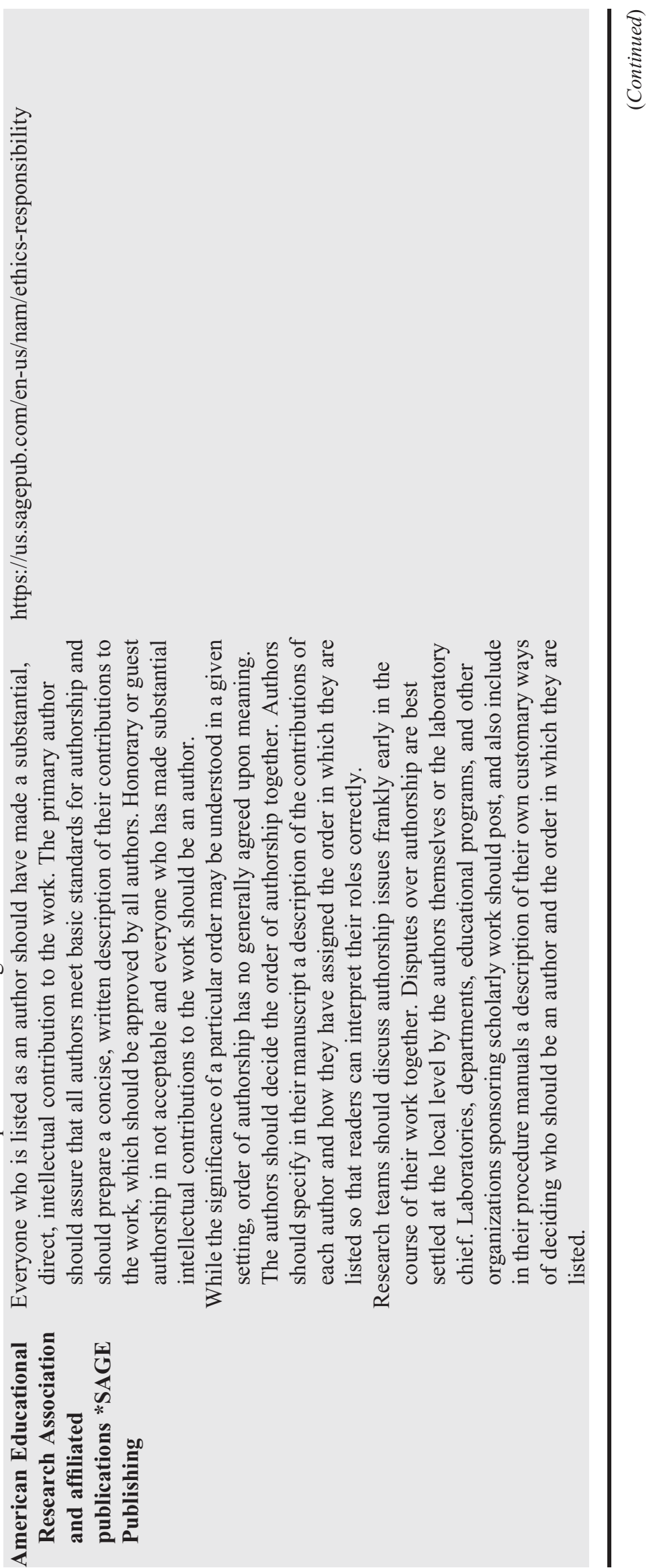
American Journal of Pharmaceutical Education 2019; 83 (6) Article 7463.

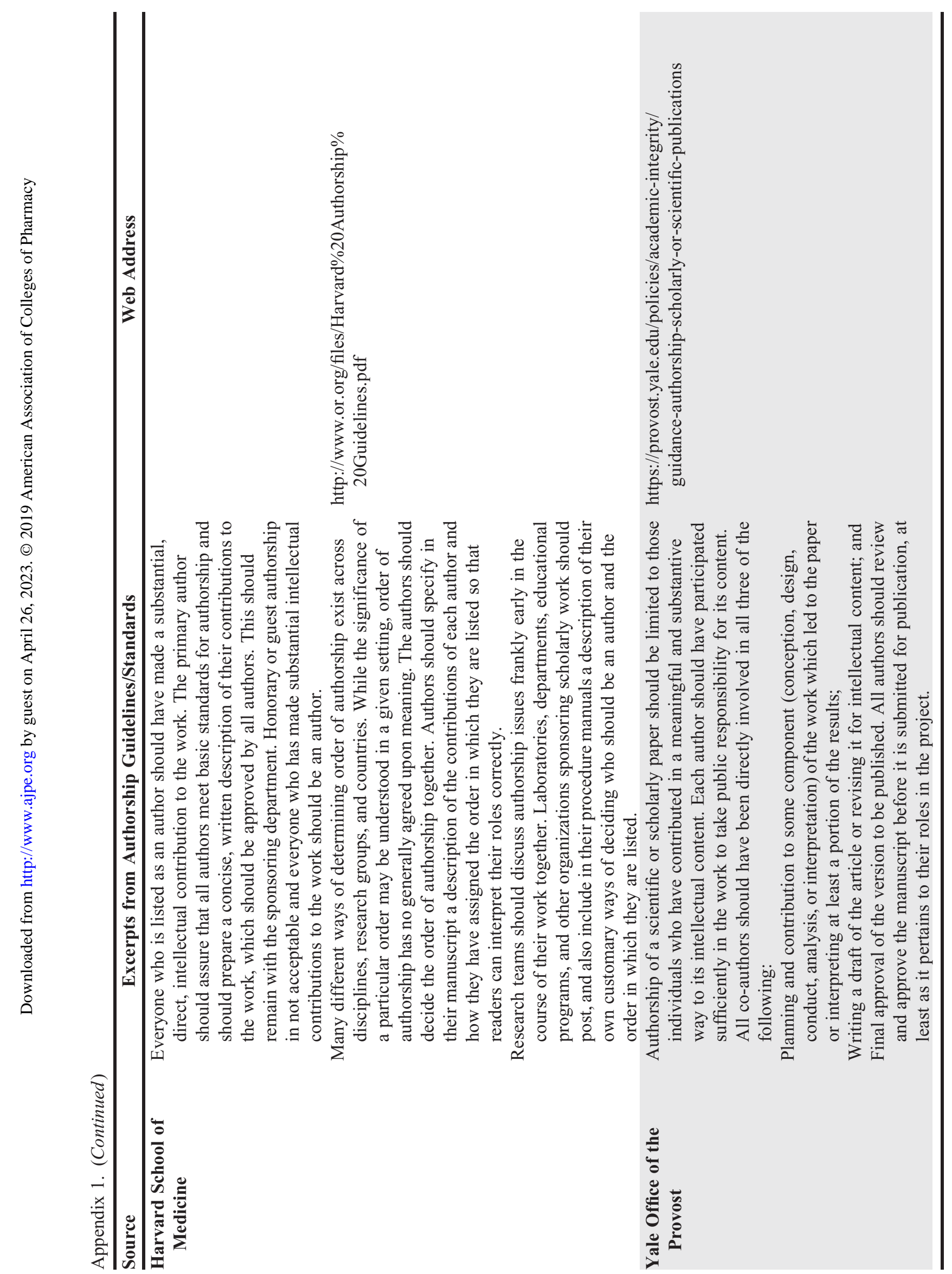

